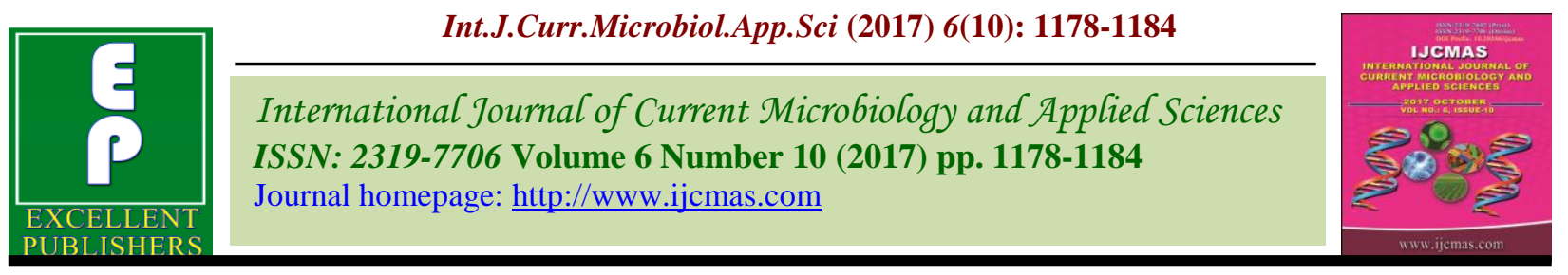

Original Research Article

https://doi.org/10.20546/ijcmas.2017.610.142

\title{
Does Rota Vaccine Reduce Attacks of Acute Gastroenteritis among Children Under 15 Months of Age?
}

\author{
Rabab Hassan Baaker ${ }^{1 *}$, Ban Adil Alkaaby ${ }^{2}$ and Shurooq Talib Sadoon ${ }^{3}$ \\ ${ }^{1}$ CABP, Department of Pediatrics, College of Medicine, Al-Mustansiryah University, Iraq \\ ${ }^{2} \mathrm{MRCPCH}$, FICMS, Department of Pediatrics, College of Medicine, Al-Mustansiryah \\ University, Iraq \\ ${ }^{3}$ FICMS-Ped., Central Teaching Hospital, Iraq \\ *Corresponding author
}

\begin{tabular}{|c|c|}
\hline \multicolumn{2}{|c|}{ A B S T RA C T } \\
\hline & \multirow{7}{*}{$\begin{array}{l}\text { This study aimed to evaluate the effect of rotavirus vaccine in reducing the attacks of acute } \\
\text { gastroenteritis among children between }(2-15) \text { months of age. A cross-sectional study was } \\
\text { carried out at the Central Teaching Hospital of Pediatrics in Baghdad, Iraq, from } 1^{\text {st }} \text { of July } \\
\text { to } 31^{\text {st }} \text { of December } 2013 \text {. } 1240 \text { patients, grouped into two groups, (618) vaccinated and } \\
\text { (622) unvaccinated group with Rota virus vaccine, aged from }>2-15 \text { months. They were } \\
\text { attending the Hospital for different reasons. Data collected about sex, age, type of feeding, } \\
\text { Rota virus vaccination status, the past medical history of acute watery diarrhea, and a } \\
\text { number of attacks that need hospitalization. In the studied sample about } 40 \% \text { of the } \\
\text { vaccinated group reported a past medical history of acute gastroenteritis, compared to } \\
\text { more than three quarters in the unvaccinated group. The need to hospital admission was } \\
\text { reduced noticeably from } 64.3 \% \text { in the unvaccinated group to } 37.2 \% \text { in the vaccinated } \\
\text { group. It was shown that children less than one year were more protected than older age } \\
\text { group. However, gender, type of feeding did not show a significant effect on the frequency } \\
\text { of gastroenteritis in both groups studied. In conclusion, The rota virus vaccination is } \\
\text { effective in reducing the attacks and the severity of gastroenteritis among children under } \\
15 \text { months of age. }\end{array}$} \\
\hline Keywords & \\
\hline $\begin{array}{l}\text { Rota vaccine, Acute } \\
\text { gastroenteritis, }\end{array}$ & \\
\hline $\begin{array}{l}\text { Diarrhoea in } \\
\text { children. }\end{array}$ & \\
\hline Article Info & \\
\hline $\begin{array}{l}\text { Accepted: } \\
\text { 10 September } 2017 \\
\text { Available Online: } \\
10 \text { October } 2017\end{array}$ & \\
\hline & \\
\hline
\end{tabular}

\section{Introduction}

Rotavirus is the most common cause of severe gastroenteritis in infants and young children. Worldwide, rotavirus is a major cause of childhood death. The spectrum of rotavirus illness ranges from mild, watery diarrhea of limited duration to severe, dehydrating diarrhea with vomiting and fever, which results in death. Virtually all children become infected in the first 3-5 years of life, but severe diarrhoea and dehydration occur primarily among children aged 3-35 months ${ }^{1}$
Rotavirus appears to be responsible for approximately $5 \%-10 \%$ of all diarrheal episodes among children aged less than 5 years, and for a much higher proportion of severe diarrheal episodes. Although rotavirus gastroenteritis results in relatively few deaths, it accounts for more than 500,000 physician visitsand approximately 50,000 hospitalizations each year among children aged less than 5 years. Rotavirus is responsible for $30 \%-50 \%$ of all 
hospitalizations for diarrheal disease among children aged less than 5 years, and more than $50 \%$ of hospitalizations for diarrheal disease during the seasonal peaks. Among children aged less than 5 years, $72 \%$ of rotavirus hospitalizations occur during the first 2 years of life, and $90 \%$ occur by age 3 years, and one in 200,000 will die from rotavirus diarrhoea (2)

Several reasons exist to adopt immunization of infants as the primary public health intervention to prevent rotavirus disease.

First, similar rates of illness among children in industrialized and less developed countries indicate that clean water supplies and good hygiene have not decreased the incidence of rotavirus diarrhea in developed countries, so further improvements in water or hygiene are unlikely to have a substantial impact. Second, a high level of rotavirus morbidity continues to occur despite currently available therapies. For example, hospitalizations for diarrhea in young children declined only 16\% from 1979 to 1992 , despite the widespread availability of oral rehydration solutions and recommendations by experts, including the American Academy of Pediatrics, for the use of oral rehydration solutions in the treatment of dehydrating gastroenteritis. Third, studies of natural rotavirus infection indicate that initial infection protects against subsequent severe diarrheal disease, although subsequent asymptomatic infections and mild disease might still occur. Thus, immunization early in life, which mimics a child's first natural infection, will not prevent all subsequent disease but should prevent most cases of severe rotavirus diarrhea and its sequelae (e.g., dehydration, physician visits, and hospitalizations) ${ }^{(3)}$.

The main of this study to evaluate the effect of rotavirus vaccine in reducing the attacks of acute gastroenteritis among children between (2-15) months of age.

\section{Patients and Methods}

A cross-sectional study was carried out at the Central Teaching Hospital of Pediatrics in Baghdad, over a period of 6 months, from $1^{\text {st }}$ of July to $31^{\text {st }}$ of December 2013.

A total of (1240) patients aged above 2 months till 15 months [(646) male, and (594) female], who were attending the outpatient for any simple illness, attended our vaccination department or admitted the hospital for acute illnesses, were studied.

All those patients were asked about sex, age, type of feeding, vaccination state, past medical history of watery diarrhea, and numbers of admission because of acute gastroenteritis.

Gastroenteritis considered positive when there is a history of acute watery diarrhea with or without vomiting, and/or fever.

They were grouped into two groups according to their vaccination status (for Rota vaccine): group (A), are those who have received Rota vaccine (as the studied group), and group (B), are those who are not (as a control group). All chronically ill children and those with bloody diarrhea, or history of bloody diarrhea, as well as partially vaccinated children (above 6 months and have received just one dose of the vaccine), were excluded from the study. Also, those cases whose mothers did not remember if their children got previous gastroenteritis.

A comparison has been made according to the number of attacks of acute gastroenteritis between the two groups, so also the attacks that need hospitalization. Then each group was divided into sub-groups according to their sex, and type of feeding, and we studied if there is any effect of these two factors on the percentage of acute gastroenteritis. 
Also, we divided each group into three subgroups according to their age:

Above 2 months-6 months (period of introduction of the vaccine).

> 6 months-12 months (period after complete vaccination).

$>12$ months -15 months (reasonable period after vaccination that the mothers could remember the past history).

A comparison of the percentage of attacks of acute gastroenteritis in each group had been done with different age groups.

The statistical method used is $p$ value according to SPSS version 13. When the $\mathrm{p}$ value is less than 0.05 , it considered significant, if less than 0.001 , it is highly significant, and if it is more than 0.05 , it is not significant.

\section{Limitations of the study}

The study was based on history taking so the mother might not exactly remember the whole events.

The study was hospital-based so the sample is not representative of the whole community.

\section{Results and Discussion}

We found that there was significantly lower frequency of AGE among babies who received Rota vaccine as compared to those who did not receive it [253 cases out of 618 who were vaccinated got attacks of gastroenteritis $(40.9 \%)$ while for unvaccinated group 480 cases out of 622 one $(77.1 \%), \mathrm{P}$ value $=0.01]$ as shown in table 1 . Regarding those cases who needed hospitalization, we found that only 94/253 patients needed hospitalization $(37.2 \%)$ in the study group while 309/480 in the control group (64.3\%) which was statically significant, so there was a significant decrease in the admission to the hospital due to acute gastroenteritis during the first 15 months of life in those who were received rotavirus vaccination. as shown in the table 2 .

This table also shows that the percentage of admission for patients with AGE of vaccinated group between age 2-6, 6-12 and $12-15$ were $39.1 \%, 38.8 \%$, and $33.3 \%$, respectively, while among those who were unvaccinated, were $71 \%, 68.3 \%$, and $51.2 \%$, respectively.

It seems that the protection is more obvious in those patients less than one-year-old compared with those aged 12-15 months [p value 0.0001 vs. 0.0162 ]

Also we found that the AGE presented in $41.8 \%$ in male, and $39.9 \%$ in female of vaccinated group, versus $75.4 \%$ in male, and $79.1 \%$ in female of unvaccinated group, so the sex had no effect on frequency of AGE, neither in those who were vaccinated nor in those were not vaccinated (Table 3 and Fig. 2). $\mathrm{P}$ value $>0.05$.

The percentage of AGE in different age groups [2-6 months, 6-12 months, and 12-15 months' age] of vaccinated patients, were $37 \%, 39.6 \%$, and $45.7 \%$ respectively, while in those unvaccinated patients were $72.3 \%$, $79 \%$, and $77 \%$, respectively, which was statistically significant as shown in table 4 .

For that patient aged 2-6m, whom the attacks of AGE were significantly less in the vaccinated group, analysis of their attacks according to the type of feeding was done and showed that there was no significant difference in the frequency of the attacks (Fig. $1)$. 
Table.1 Distribution of cases of AGE both in the study and control groups

\begin{tabular}{|c|c|c|c|}
\hline Title & $\begin{array}{c}\text { Total } \\
\text { No. }\end{array}$ & $\begin{array}{c}\text { No. patients } \\
\text { with AGE }\end{array}$ & Percentage (\%) \\
\hline $\begin{array}{c}\text { Group (A) } \\
\text { Vaccinated group }\end{array}$ & $\mathbf{6 1 8}$ & $\mathbf{2 5 3}$ & $\mathbf{4 0 . 9 \%}$ \\
\hline $\begin{array}{c}\text { Group (B) } \\
\text { Not vaccinated group }\end{array}$ & $\mathbf{6 2 2}$ & $\mathbf{4 8 0}$ & $\mathbf{7 7 . 1 \%}$ \\
\hline
\end{tabular}

$P$ value $=0.01$. (Significant)

Table.2 Distribution of study group by admission to hospital due to acute gastroenteritis according to state of vaccination and age

\begin{tabular}{|c|c|c|c|c|c|c|c|}
\hline \multirow{2}{*}{$\begin{array}{c}\text { Age } \\
\text { (months) }\end{array}$} & \multicolumn{3}{|c|}{$\operatorname{group}(\mathbf{A})$} & \multicolumn{3}{|c|}{ group (B) } & \multirow[b]{2}{*}{ P-value } \\
\hline & $\begin{array}{c}\text { No. of } \\
\text { AGE pt. }\end{array}$ & $\begin{array}{c}\text { No. of } \\
\text { admission }\end{array}$ & $(\%)$ & $\begin{array}{c}\text { No. of } \\
\text { AGE pt. }\end{array}$ & $\begin{array}{c}\text { No. of } \\
\text { admission }\end{array}$ & $(\%)$ & \\
\hline $2-6$ & 67 & 27 & $39.1 \%$ & 107 & 76 & $71.02 \%$ & 0.0001 \\
\hline 6-12 & 90 & 35 & $38.8 \%$ & 246 & 168 & $68.3 \%$ & 0.0001 \\
\hline $12-15$ & 96 & 32 & $33.3 \%$ & 127 & 65 & $51.2 \%$ & 0.0162 \\
\hline Total & 253 & 94 & $37.2 \%$ & 480 & 309 & $64.3 \%$ & \\
\hline
\end{tabular}

Table.3 Sex distribution of study and control groups

\begin{tabular}{|c|c|c|c|c|c|c|c|c|}
\hline \multirow{2}{*}{$\begin{array}{c}\text { Status of } \\
\text { vaccinated } \\
\text { patients }\end{array}$} & \multicolumn{3}{|c|}{ Male } & \multicolumn{3}{c|}{ Female } & \multirow{2}{*}{$\begin{array}{c}\text { Total } \\
\text { NO. }\end{array}$} & P-value \\
\cline { 2 - 9 } & $\begin{array}{c}\text { Total } \\
\text { NO. }\end{array}$ & & $(\%)$ & $\begin{array}{c}\text { Total } \\
\text { NO. }\end{array}$ & & $(\%)$ & & \\
\hline $\begin{array}{c}\text { Group (A): } \\
\text { Vaccinated }\end{array}$ & 320 & 134 & $41.8 \%$ & 298 & 119 & $39.9 \%$ & 618 & 0.744 \\
\hline $\begin{array}{c}\text { Group (B): Not } \\
\text { vaccinated }\end{array}$ & 326 & 246 & $75.4 \%$ & 296 & 234 & $79.1 \%$ & 622 & 0.693 \\
\hline Total & 646 & 380 & $58.8 \%$ & 594 & 353 & $59.4 \%$ & 1240 & \\
\hline
\end{tabular}

Table.4 Age distribution of the studied groups

\begin{tabular}{|l|l|l|l|l|l|l|l|}
\hline \multirow{2}{*}{$\begin{array}{c}\text { Age } \\
(\text { months) }\end{array}$} & \multicolumn{3}{|c|}{ Group (A) } & \multicolumn{3}{c|}{ Group (B) } & \\
\cline { 2 - 8 } & $\begin{array}{c}\text { Total } \\
\text { No. }\end{array}$ & $\begin{array}{c}\text { Pt. with } \\
\text { AGE }\end{array}$ & $(\%)$ & $\begin{array}{c}\text { Total } \\
\text { No. }\end{array}$ & $\begin{array}{c}\text { Pt. with } \\
\text { AGE }\end{array}$ & $(\%)$ & $\begin{array}{c}\text { P } \\
\text { value }\end{array}$ \\
\hline $2-6$ & 181 & 67 & $37 \%$ & 148 & 107 & $72.3 \%$ & 0.0001 \\
\hline $6-12$ & 227 & 90 & $39.6 \%$ & 311 & 246 & $79 \%$ & 0.0001 \\
\hline $12-15$ & 210 & 96 & $45.7 \%$ & 163 & 127 & $77 \%$ & 0.0001 \\
\hline Total & 618 & 253 & 40.9 & 622 & 480 & $77.2 \%$ & 0.0001 \\
\hline
\end{tabular}


Table.5 Frequency of acute gastroenteritis in studied groups in related to types of feeding for infants 2-6 months of age

\begin{tabular}{|c|c|c|c|c|c|c|}
\hline \multirow[t]{2}{*}{ Type of feeding } & \multicolumn{3}{|c|}{ Group (A) } & \multicolumn{3}{|c|}{ Group (B) } \\
\hline & Total No. & $\begin{array}{l}\text { Pt. with } \\
\text { AGE }\end{array}$ & $(\%)$ & Total No. & $\begin{array}{c}\text { Pt. with } \\
\text { AGE }\end{array}$ & $(\%)$ \\
\hline Exclusive breast feeding & 53 & 19 & $35.8 \%$ & 41 & 28 & $68.3 \%$ \\
\hline Bottle feeding & 66 & 25 & $37.8 \%$ & 56 & 40 & $71 \%$ \\
\hline Mixed feeding & 62 & 23 & $37.1 \%$ & 51 & 39 & $76.5 \%$ \\
\hline Total & 181 & 67 & $37 \%$ & 148 & 107 & $72.3 \%$ \\
\hline & P-value & & & P-value & & \\
\hline
\end{tabular}

Fig.1 Frequency of AGE in both groups

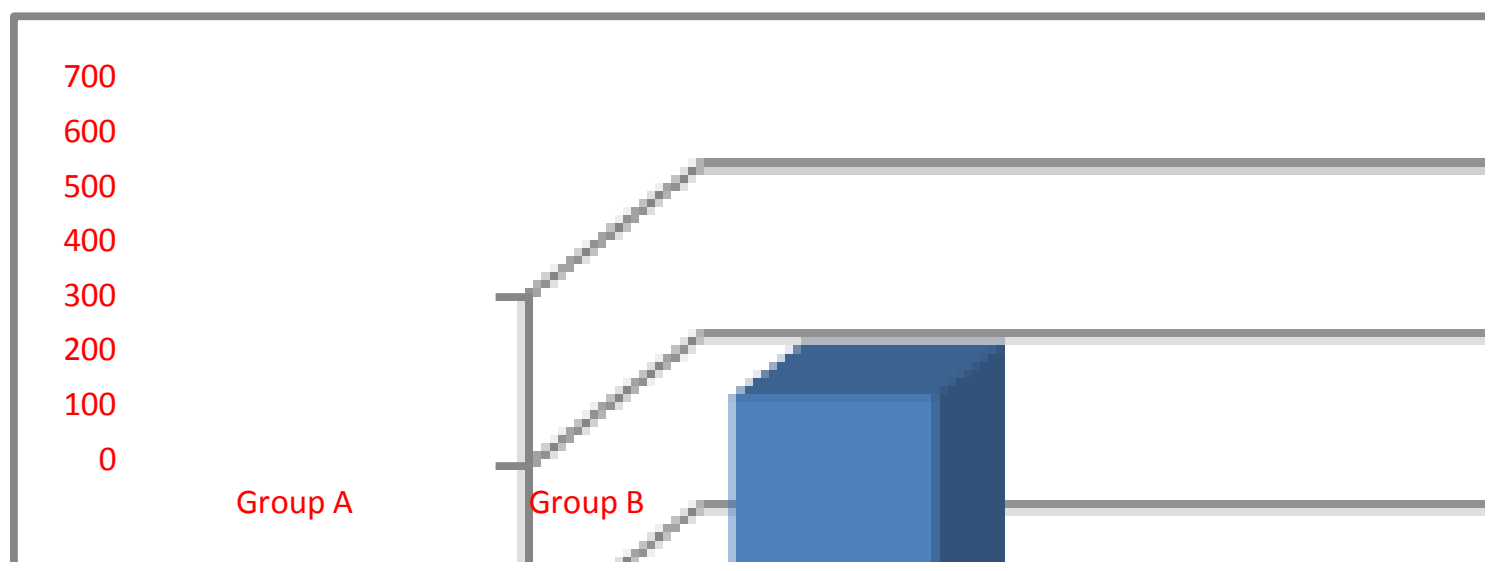

Fig.2 Distribution of patients according to their sex

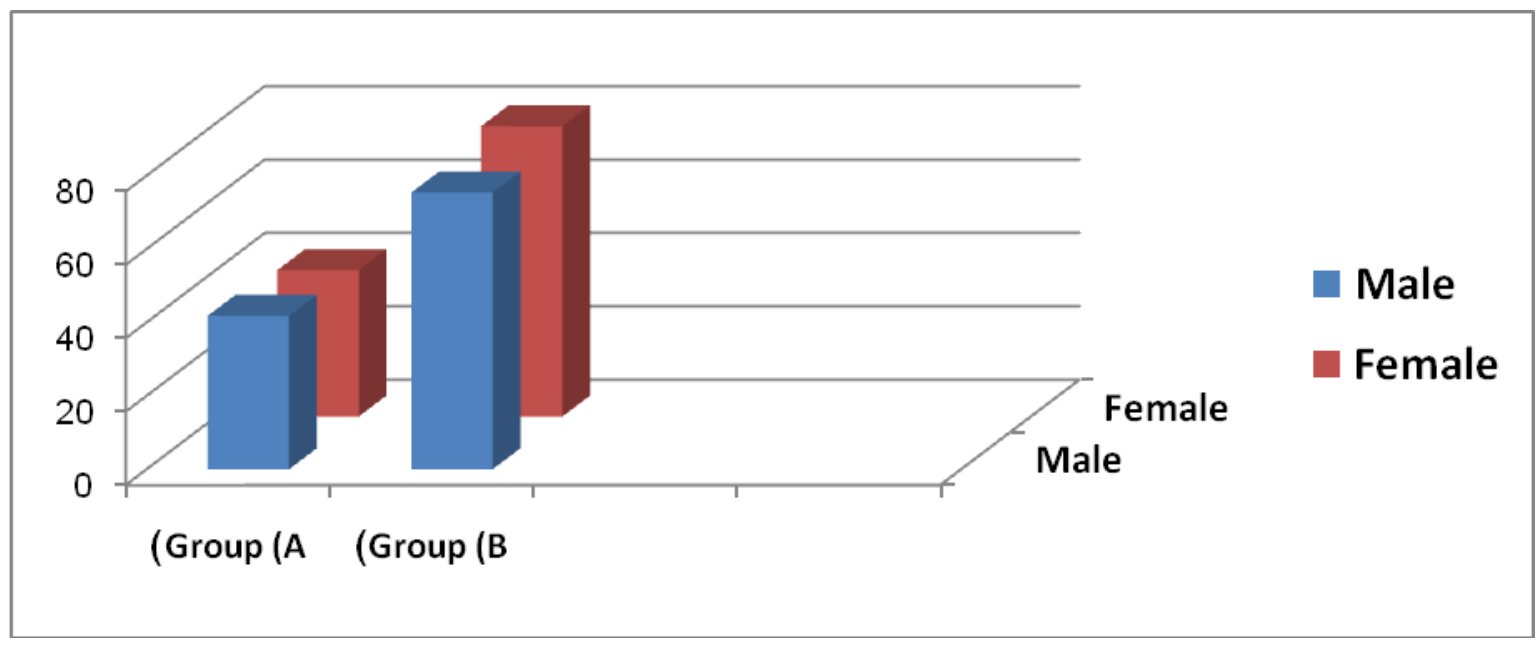

There was slight difference in percentage of AGE in children who were exclusive breast, bottle, and mixed feeding in both vaccinated
$(35.8 \%, 37.8 \%$, and $37 \%$ respectively), and unvaccinated patients $(68.3 \%, 71 \%$, and $76.5 \%$ respectively), but this difference was 
statically not significant $(\mathrm{P}$-value $>0.05)$ (Table 5), so the types of feeding for infants 2-6 months of age had no significant effect on frequency of acute gastroenteritis in related to rotavirus vaccine in studied groups.

A cross-sectional study shows that the frequency of acute gastroenteritis was lower in patients who received rota virus vaccine (40.9\%), compared with those who did not receive the vaccine $(77.1 \%)$, and this difference, which is statistically significant, is similar to study done in U.S.A, which estimates the effectiveness of the pentavalent rotavirus vaccine observed in cross-sectional studies undertaken in the U.S ${ }^{(4)}$. With the effectiveness of two doses of the monovalent rotavirus vaccine against rotavirus gastroenteritis being $76 \%$ in El Salvador ${ }^{(5)}$, and an overall efficacy of the monovalent rotavirus vaccine in preventing episodes of severe rotavirus gastroenteritis of $61 \%$ in a clinical trial that was designed to simulate real world conditions of use in Malawi and South Africa $^{(6)}$.

This study shows that there is no relation between the rotavirus vaccine and certain age group including $>2-6,6-12$, and 12-15 months, for both studies groups, this result is nearly equal or similar to another study in Central Australia, that's found no difference in effectiveness between children aged 3-11 months and those aged 12 months or older that have suggested vaccine effectiveness might decrease slightly during the second year of life ${ }^{(7)}$.

This study shows that the gender had no effect on the frequency of acute gastroenteritis in both studies groups. This result is nearly equal to study performed in Al-Bahrain by Dutta et al., 1990, which estimate no significant difference between males and females (males are slightly higher than females) ${ }^{(8)}$.
This study also shows that there is no significant effect between the type of feeding and the incidence of acute gastroenteritis for infants aged 2-6 months for both groups. Unlike other studies were done in the Philippines ${ }^{(9)}$, Tehran ${ }^{(10)}$, and Mexico City (11). These studies show that a low rate of acute watery diarrhea in infants under six months of age has been attributed to a higher rate of breast feeding in this age group, which is due to the passive immunity that the infant received from his mother. The difference in our study may be explained by many factors, like no accurate reality of exclusive breast feeding because many mothers denied, poor mothers-babies care, and hygiene, and the introduction of early weaning food, which may be contaminated by enteropathogens. The diff erence in our study may be explained by the small number of babies who were exclusively breastfed.

In patients who received rotavirus vaccine, there was a significant effectof lowering the number of admission to the hospital due to acute watery diarrhea, unlike those who have not received the vaccine. This result is similar to study performed in Belgium, showed that rotavirus vaccination is effective for the prevention of admission to hospital for rotavirus gastroenteritis among young children. Results of an intention to vaccinate analysis showed that at least one dose of any rotavirus vaccine can provide $91 \%$ protection against hospital admission ${ }^{(12)}$. This study is in line with the reported reduction in the number of admissions attributable to rotavirus gastroenteritis in a regional Belgian hospital that was not selected for participation in this study. In Latin America, the US, Europe, and Australia considerable reductions in rotavirus infections and related admissions among young children have been reported after introduction of rotavirus vaccine ${ }^{(13,14,15,16,17)}$, with vaccination associated with a significant decline in overall deaths related to diarrhea 
among children aged under 5 in Mexico ${ }^{(18)}$.

There is a significant reduction of attacks of acute gastroenteritis after the introduction of Rota vaccine in our community.

The effect of vaccination was obvious even in the period of vaccine evolution.

\section{References}

Ballal M, Shivananda PG. 2002. Rotavirus in infantile diarrhea in Manipal, South India. Indian J Pediatric; 69(5):393-6.

Boom JA, et al., 2010. Effectiveness of pentavalent rotavirus vaccine in a large urban population in the United States. Pediatrics; 125:199-207.

Buttery JP, et al., 2011. Reduction in rotavirusassociated acute gastroenteritis following introduction of rotavirus vaccine into Australia's National Childhood vaccine schedule. Pediatric Infect Dis J; 30(suppl 1): S25-9.

De Palma O, et al., 2010. The effectiveness of rotavirus vaccination against childhood diarrhea in El Salvador: acase-control study. BMJ; 341:c2825.

Dutta, S., et al., (1990). Epidemiology of Rotavirus dirrhoea in children under five years in Bahrain. Intern. 19:722.

Field EJ, et al., 2010. Pentavalent rotavirus vaccine and prevention of gastroenteritis hospitalizations in Australia. Pediatrics; 126: e506-12.

Glass RI, Bresee J, et al., 2006. Rotavirus and rotavirus vaccines. AdvExp Med Biol; 582:45-54.

Mahdi SA, et al., 2010. Effect of human rotavirus vaccine on severe diarrhea in African infants. N Engl J Med; 362:289-98.
Malek MA, et al., 2006. Diarrhea-and rotavirusassociated hospitalizations among children less than 5 years of age: The United States, 1997 and 2000. Pediatrics; 117:1887-1892.

Paje-Villar E, et al., 1994. Non-bacterial diarrher in children in the Philippines. Ann Trop Med Parasitol; 88(1):53-8.

Paulke-Korinek M, et al., 2010. Universal mass vaccination against rotavirus gastroenteritis: impact on hospitalization rates in Austrian children. Pediatric Infect Dis J; 29:319-23.

Puerto FI, et al., 1989 Role of rotavirus and enteric adenovirus in acute pediatric diarrhea at an urban hospital in Mexico. Trans R Soc Trop Med Hyg; 38(3): 396-8.

Quintanar-Solares M, et al., 2010. Impact of rotavirus vaccination on diarrhea-related hospitalizations among children $<5$ years of age in Mexico. Pediatric Infect Dis $\mathrm{J}$; 30(suppl 1): S11-5.

Rimoldi SG, et al., 2011. Epidemiological and clinical characteristics of pediatric gastroenteritis associated with new viral agents. Arch Virol; 156:1583-9.

Snelling TL, et al., 2011.Case-control evaluation of the effectiveness of the G1P [8] human rotavirus vaccine during an outbreak of rotavirus G2P [4] infection in Central Australia. Clin Infect Dis; 52:191-9.

Tate JE, et al., 2009. Decline and change in seasonality of US rotavirus activity after the introduction of rotavirus vaccine. Pediatrics; 124:465-71.

Zarnani AH, et al., 2003 Role of rotaviruses in children with acute diarrhea in Tehran, Iran. J ClinVirol; 30:1-6.

Zeller M, et al., 2010. Rotavirus incidence and genotype distribution before and after national rotavirus vaccine introduction in Belgium. Vaccine; 28:7507-13.

\section{How to cite this article:}

Rabab Hassan Baaker, Ban Adil Alkaaby and Shurooq Talib Sadoon. 2017. Does Rota Vaccine Reduce Attacks of Acute Gastroenteritis among Children Under 15 Months of Age? Int.J.Curr.Microbiol.App.Sci. 6(10): 1178-1184. doi: https://doi.org/10.20546/ijcmas.2017.610.142 